\title{
Characteristic Alterations in Responses to Imposed Wrist Displacements in Parkinsonian Rigidity and Dystonia Musculorum Deformans
}

\author{
W.G. Tatton, W. Bedingham, M.C. Verrier and R.D.G. Blair
}

\begin{abstract}
The amplitude and temporal modulation of the segmented EMG activity in flexor carpi radialis, evoked by imposed angular wrist extension, was studied with respect to the level of pre-existing background activity in rigid parkinsonian (PK) and dystonia musculorum deformans (DMD) patients. The interdependence of the evoked MI and M2-3 segments on pre-existing background EMG activity and initial velocity of imposed displacement was established previously for a normal population. Individual responses of 21 parkinsonian and 12 dystonic patients were compared to the established normal "response volume". The augmented magnitude of the M2-3 segment in rigid PK patients, which correlates to the measure of rigidity, could not be accounted for by the low level of pre-existing EMG activity. Therefore, increased descending facilitation does not impinge directly on alpha motoneurons. Paradoxical excitation in the shortened muscle and resetting of tonic tremor of the stretched muscle by the imposed wrist extension are two other demonstrated abnormalities which may also contribute to PK rigidity. In contrast, DMD patients demonstrated normal amplitude modulation of the M1 and M2-3 segments, but exhibited a disturbance of normal temporal mechanisms that result in constant duration of the MI and M2-3 responses with imposed force step loads.
\end{abstract}

RÉSUMÉ: Nous avons étudié chez patients qui souffraient de la rigidité parkinsonnienne ou de dystonie musculaire déformante, l'amplitude et la modulaton temporale de l'activité segmentaire EMG du muscle "flexor carpi radialis", evoquées par l'extension imposée angulaire du poignet, à l'égard du niveau de l'activité d'arrière-plan pré-existant. L'inter-dépendence des segments évoqués M2 et M2-3 sur l'activité EMG pré-existant fut décrit antérieurment chez une population normale. Les réponses individuels du 21 patients parkinsonniens et 12 patients dystoniques furèrent comparées à les variations de témoins normaux. La magnitude augmentée du segment M2-3 chez les patients rigides parkinsonniens, ce qui bien correspond à la quantité de rigidité, ne pouvait pas s'expliquer par le neveau bas d'activité EMG pré-existant. Ainsi que la facilitation descendante augmntée n'affecte pas directement les motoneurones alpha. L'excitation paradoxale dans le muscle raccourci et la restauration du tremblement tonique du muscle tendu par l'extension imposée du poignet sont deux autres anomalies montrées qui porraient contribuer aussi à la rigidité parkinsonnienne. Par contre, les patients dystoniques montraient la modulation d'amplitude normale des segments MI et M2-3, mais exhibaient une anomalie des mécanismes temporaux qui résultent à une durée constante des réponses M1 et M2-3 à les charges imposées.

Can. J. Neurol. Sci. 1984; 11:281-287

The segmented electromyographic (EMG) activity evoked by imposed joint displacements has been reported to be abnormal in three movement disorders involving alterations in muscle tone. Firstly, in parkinsonian rigidity, the long-latency M2-3 segments appear to be increased in size while the initial MI segments remain normal (Tatton and Lee, 1975; Mortimer and Webster, 1978; Chan et al., 1979; Rothwell et al., 1983; Berardelli et al., 1983a; Struppler et al., 1984). Secondly, a proportion of hemiplegic patients following cerebral vascular accidents appear to show increased initial or M1 segments (Lee and Tatton, 1978; Berardelli et al., 1983b; Verrier et al., 1984). Finally, patients with Huntington's chorea have absent or reduced long latency (M2) segments (Noth et al., 1983).

The augmentation of the M2-3 segments in rigid parkinsonians has been dismissed by some investigators (see Delong and Georgopoulos, 1981 for a detailed discussion) following the suggestion that high baseline or tonic levels of EMG in the stretched muscle is sufficient to account for the increases due to concomitant alteration in motoneuron excitability (Evarts et al., 1979). This suggestion is based on the observation that elderly normals (mean age of 67.1 years) appeared to show both heightened M2-3 segments and high resting levels of EMG

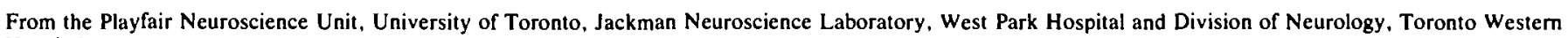
Hospital

Received November 10, 1983. Accepted for publication March 5, 1984

Reprint requests to: Dr. W.G. Tatton, Playfair Neuroscience Unit. Toronto Westem Hospital, 399 Bathurst Street. Toronto, Ontario M5T 2S8 
activity, as compared to younger normals, apparently being unable to relax adequately.

In a companion paper, "response planes" which relate the magnitude of the M1 and the M2-3 segments simultaneously to the background or tonic level of EMG activity in the stretched muscle and the initial velocity of the imposed joint displacement were presented. The planes provide a means of quantitatively assessing the relative effect of pre-existing levels of EMG activity in the stretched muscles on the segmented responses (Bedingham and Tatton, 1984). "Response volumes"' have also been calculated for populations of normal subjects which should enclose all of their individual response planes, and can potentially be used to determine if the magnitude of the response segments recorded in individual subjects differs significantly from the normal population. The normal studies also showed that the segmented responses to wrist displacements imposed by force step loads, although jointly amplitude modulated by the mechanical parameters and pre-existing EMG levels, are of constant duration despite several fold variations in the duration of the imposed movements.

These approaches for quantitative analysis of amplitude and duration control of the segmented reflex responses provide a means of testing the proposal of Evarts et al. (1979) regarding the long latency segments in parkinsonian patients. Accordingly, we examined the EMG responses to imposed wrist displacements in a series of rigid parkinsonian patients. In order to obtain comparative results we also examined both response amplitude modulation and duration control in patients with another extrapyramidal disorder, dystonia musculorum deformans (DMD).

The study established that increased levels of tonic EMG activity cannot account for the increased M2-3 segments in parkinsonian rigidity and response duration control is intact in this form of rigidity. In contrast, patients with DMD show an apparent disturbance of the mechanisms that result in constant duration of the segmented responses in normals while amplitude modulation appears normal.

\section{METHODS}

A total of 21 parkinsonian (PK) patients ranging in age from 35 to 72 years together with 12 DMD patients ( 14 to 40 years of age) were examined. All the patients were independently assessed by the same neurologist prior to electrophysiological evaluation. The PK patients were chosen because their predominant deficits were bradykinesia and rigidity. Rest tremor sufficient to prevent the patient from maintaining the wrist in a constant angular position precluded analysis (see below). The majority of the PK patients (18/21) were being treated with L-Dopa.

Only patients appearing to have the classic form of DMD (Marsden et al., 1976) re were included in the results presented in this paper. Five of the twelve patients had undergone thalamotomy. In the case of unilateral thalamotomies, recordings from the wrist musculature contralateral to the thalamic lesion were not utilized for the results presented in this paper.

The patients were studied using the same apparatus, recording methods and computer analysis techniques described in detail for a normal population in the companion manuscript (Bedingham and Tatton, 1984). Briefly, angular step load displacements were imposed on the wrist joint by a computer controlled torque motor. Electromyographic activity was differ- entially recorded by surface electrodes placed over flexor carpi radialis (FCR) and extensor digitorum communis (EDC). Wrist position records and EMG activity were simultaneously recorded and analyzed. The magnitude of evoked reflex EMG activity above the pre-existing background level was normalized with respect to maximum voluntary activation (\% MVA). As a measure of imposed mechanical input, the initial velocity (IV) of the displacement was computed (i.e. mean velocity during initial 35 $\mathrm{ms}$ ) prior to the onset of the earliest reflex activity. Latencies and terminations of the EMG segments were measured from the points of intersection of the 3.0 standard deviation level above mean background EMG with the averaged traces. The mean magnitude of each reflex segment (i.e. M1 and M2-3) was plotted against the pre-existing level of background EMG activity and the IV of the displacement. This interdependent relationship was then compared to the range of values established previously for a normal population, which was represented graphically as a volume relating these three variables.

\section{RESULts}

Figure 1 presents the age distribution for the thirty normal subjects studied in the companion paper (Bedingham and Tatton, 1984) together with that for the nine selected parkinsonian patients whose data will be used to illustrate our findings. The nine were chosen (with one exception indicated by an asterisk) because of their relatively young age in order to avoid the potential interpretive difficulties related to Evarts et al. (1979) suggestion that the increased M2-3 segments were a feature of the responses in the elderly.

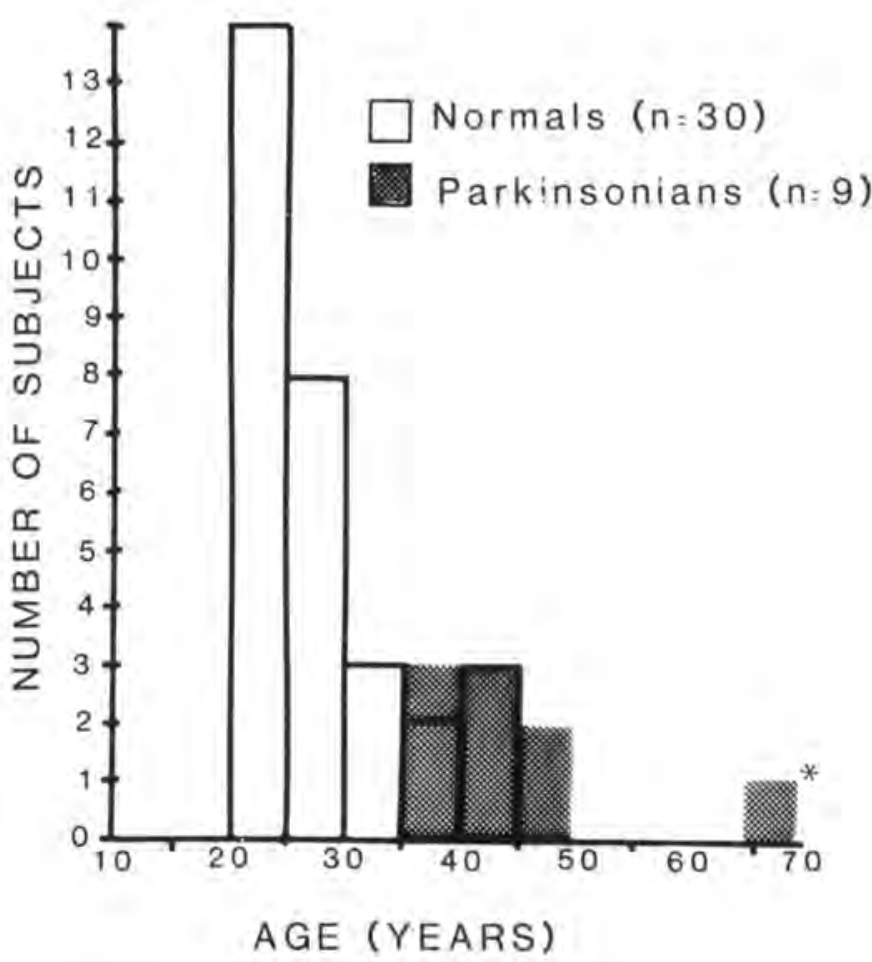

Figure I - Age distribution of the normal subjects used for calculation of the response volumes (open bars) together with that for the PKs (shaded bars) whose $M 1$ and $M 2-3$ values are illustrated in figures 3 and 4. 
Figure 2 presents a typical set of records for wrist displacements stretching FCR. The values at the left end of the position averages show the IVs. Background EMG (BKGD\%) values are expressed as percentage of maximum voluntary activation (MVA) at the left end of the EMG averages, while MI and M2-3 segment magnitudes above background level are shown at the right end of each record (RFLX\%). The traces show that the MI segments are small (increasing from I - 4\% MVA) in keeping with the low background levels (1.6-2.0\% MVA) as would be predicted by the $\mathrm{MI}$ response planes constructed for the population of normal subjects (see Bedingham and Tatton, 1984). In contrast, the M2-3 segments are extremely prominent and demonstrate minimal amplitude modulation for IV s exceeding $93 \% \mathrm{sec}$. when compared to the monotonic grading found for normals over the IV range of 46 to $188^{\circ} / \mathrm{sec}$. In short, the responses for the rigid parkinsonian illustrated in figure 2 show M2-3 segments with amplitudes exceeding those found in normals at background levels of as high as $14 \%$ MVA while the M1 segments amplitudes appear to be within the range of normals for the background levels.

\section{PARKINSONIAN FCR}

\section{position}
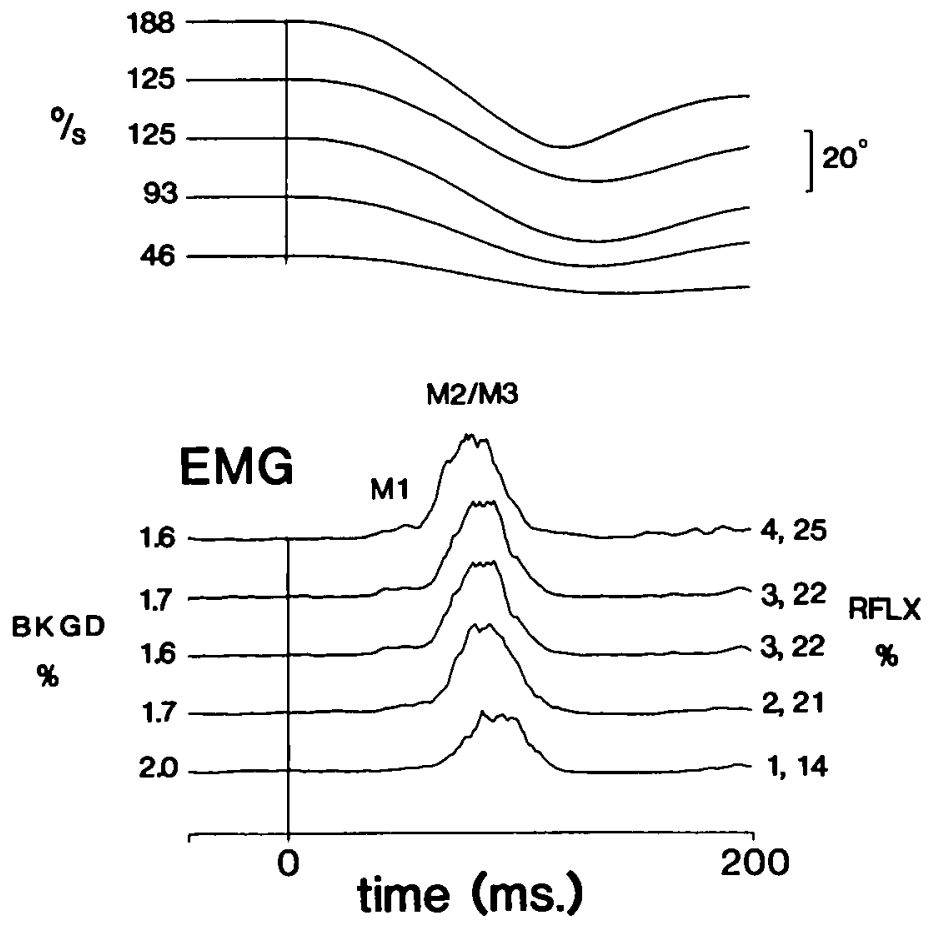

Figure 2 - Average records for angular displacement imposed on the wrist of a rigid $P K$. The numerals at the left end of the position record present the mean velocity over the initial $35 \mathrm{msec}$ of the imposed movement. The value at the left end of the EMG activity expresses $B K G D$ activity as a percentage of the maximum voluntary activity (\%MVA) for the stretched muscle, $F C R$. The numbers at the right end of the EMG activity present the magnitude above background level for the $M I$ and $M 2-3$ segments.
In order to explore the relationship between M2-3 amplitude and clinical rigidity the nine young PKs presented in the age distribution were separated into two groups according to the severity of rigidity that could be detected clinically in the wrist musculature. Patients with +4 rigidity were not included in this group since the degree of rigidity was sufficient to prevent an adequate range of IVs from being examined. A scale of $0-4$ was used according to the following criteria:-

$0=$ Absent.

$+1=$ Slight or detectable only when activated by contralateral wrist movements.

$+2=$ Mild to moderate.

$+3=$ Marked, but full range of movement easily achieved.

$+4=$ Severe, range of motion achieved with difficulty.

Figures 3 and 4 present data from four PK patients with minimal rigidity (grade $0,+1$ ) over-plotted on normal response volumes in the left sides of the figures (labelled NON RIGID) while the plots on the right sides are for five PK patients with mild to moderate rigidity (grade $+1,+2$ or $+2,+3$; labelled RIGID). The response volumes were calculated for the $M 1$ and M2-3 segments in the normal population (Bedingham and Tatton, 1984). Both figures present average response values of five different BKGD-IV measurements for each patient. Different symbols for each patient are plotted relative to the normal volumes.

All MI segment values fall just below or within the volumes for both the RIGID and NON RIGID patients with one exception. Three of the values for the 72 year old patient just exceed the upper surface of the normal volume (the reason for this patient's inclusion is that she was the only PK studied to date whose MI values have exceeded the upper surface). In marked contrast all of the M2-3 values for the RIGID PKs exceed the upper surface volume while those for the NON RIGID patients are either just beneath or within the volume.

In particular, note that the M2-3 values exceed the normal response volumes for all values of background EMG, even those below 4\% MVA. This clearly demonstrates that increased tonic levels of EMG activity in the stretched muscle are not a prerequisite for increased M2-3 segments as proposed by Evarts et al. (1979). Furthermore, the Ml segment values are not increased above the normal volumes in the RIGID PKs for the same background levels of activity.

The parkinsonian patients demonstrated two other abnormalities to the imposed wrist displacements as described previously (Lee and Tatton, 1975; Tatton et al.. 1979). These are illustrated in figure 5 . The averaged records in this figure have a $630 \mathrm{msec}$ time base after the onset of the randomly-timed wrist displacements. The first abnormality is a phasic increase in EMG activity in the shortened muscle (in this case EDC) at about the same time as the increased M2-3 segment in the muscle being stretched (FCR). This "paradoxical" excitation (termed as the Westphal phenomenon) can be seen in some normals, although less prominently. The second abnormality consists of a six to ten hz oscillation in the EMG activity subsequent to the increased M2-3 segment in the stretched muscle (the first burst between 30 and $105 \mathrm{msec}$ is the $\mathrm{MI}$ and M2-3 segments, while in this case the peak to peak interval between the subsequent three cyclic bursts in the average is $160 \mathrm{msec}$ ). The bursts typically "damped out" after four to six cycles. Since the imposed step loads were presented randomly in time, the oscillatory activity represents 
NON RIGID

FCR M 1

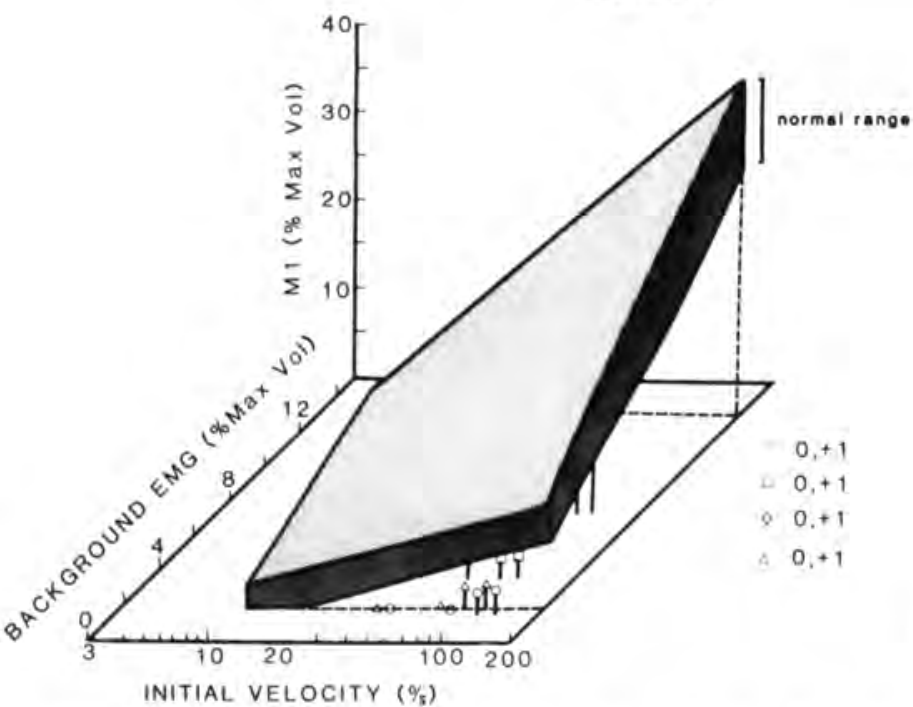

RIGID

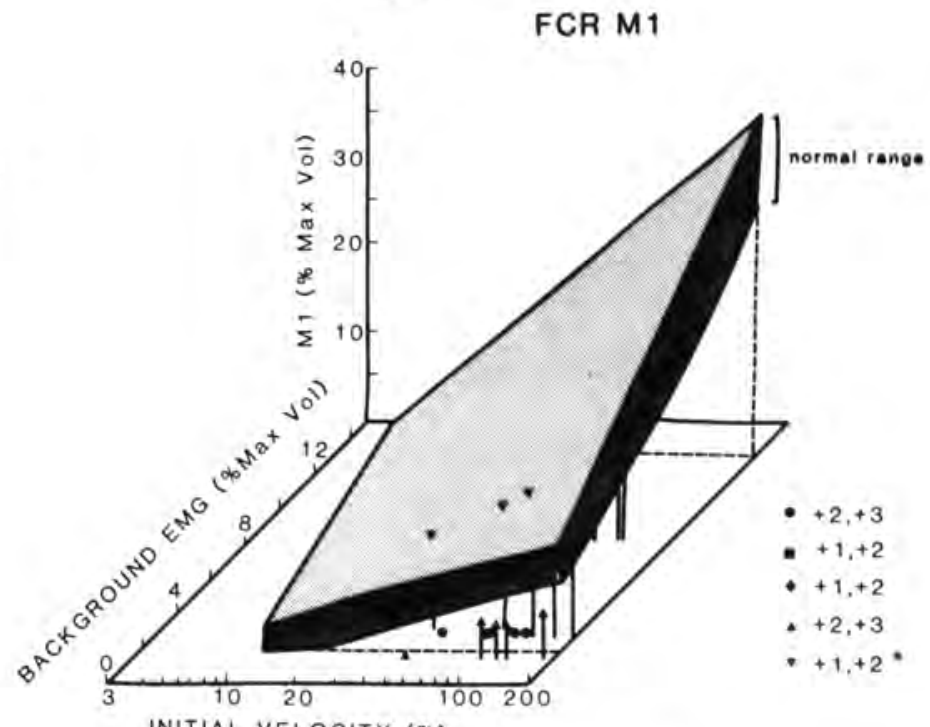

INITIAL VELOCITY (7/s)

Figure 3 - Response volumes for a normal population taken from Bedingham and Tatton (1984). Five BKGD-IV measurements for the FCR MI segments in NON RIGID and RIGID PK's are superimposed.

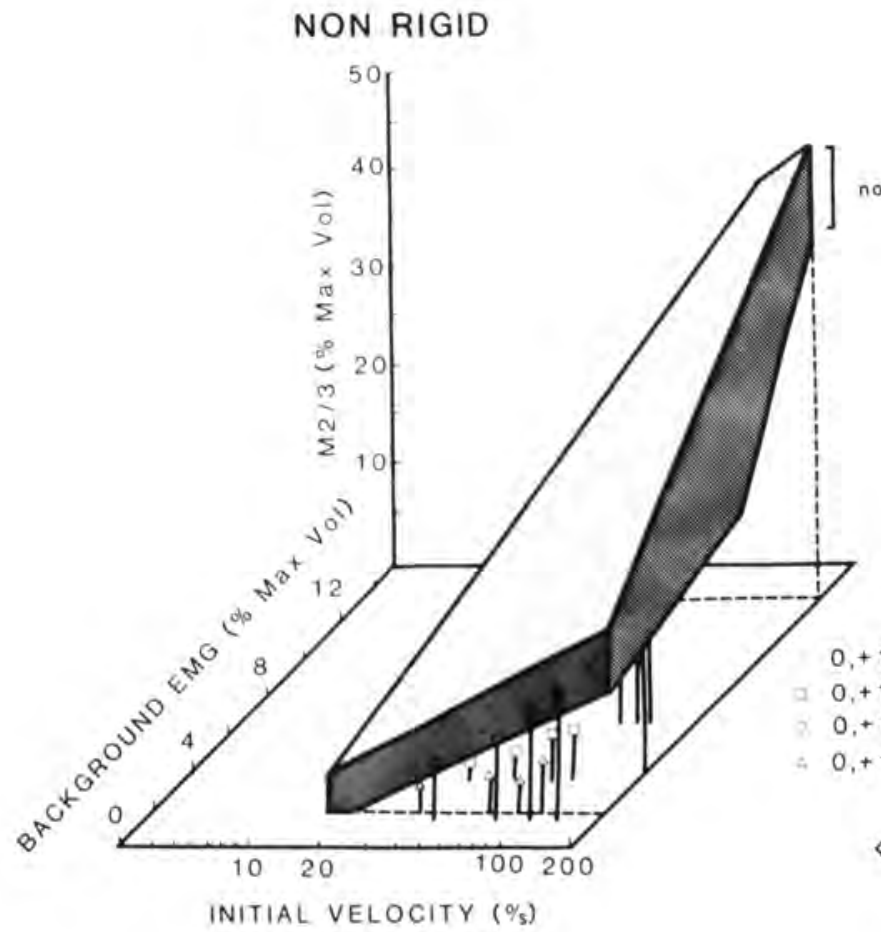

Figure 4 - Similar to figure 3 with the values plotted for the M2-3 segments.

a "resetting" of a tonic tremor or the initiation of oscillatory activity, as is evidenced by the "flat" baseline to the left of time 0 (see Stein and Lee, 1981 for a discussion of resetting of tremor).

DMD patients showed a consistent abnormality different from that found in the rigid PKs. A typical example is presented in figure 6. The labelling conventions are the same as those in figure 2. This patient shows moderately high background EMG levels (5.4\%-10.9\%). The M1 segment has a normal latency and grades monotonically from $13-23 \%$ MVA for IVs varying from 87 to $204 \% \mathrm{sec}$. Although the mean level of long latency activity (labelled M2/M3p) is similarly graded (increasing from $20-29 \%$ MVA for the same IV values), it is prolonged and appears to continue as long as the imposed movement is in progress. This 
continued activity is in sharp contrast to the constant segment terminations found for step load imposed displacements in both normals (Bedingham and Tatton, 1984) and rigid PKs (see figure 2).

The prolonged long latency activity makes the data inappropriate to superimpose on response volumes for the normal M2-3 segments. Input-output plots show that the slope of the graded responses increases with BKGD levels in a manner similar to normals (Bedingham and Tatton, 1984). Typical examples are presented for four DMDs in figure 7 for both the $\mathrm{M} 1$ and the prolonged long latency activity labelled $M 2 / 3 p$.

Figure 8 best illustrates the characteristic duration abnormality found in the DMD patients. Although the M1 segment latency remains constant to within $\pm 2 \mathrm{msec}$ as in normals (the shaded regions show the range of values for normal subjects taken from Bedingham and Tatton, 1984), the duration of summed M1 and M2-3p activity (labelled M1/2/3p duration) decreases almost proportionally to the duration of the imposed displacement (as shown by comparing the plots for displacement duration and $M 1 / 2 / 3 p$ durations). This is in contrast to normals whose $\mathrm{MI} / 2 / 3$ duration is constant within $\pm 2 \mathrm{msec}$ irrespective of the displacement duration.

\section{Discussion}

The response volume analysis of M2-3 segments for rigid parkinsonian patients establishes that the increased M2-3 segment in these patients is not merely a reflection of high tonic levels of alpha motoneuron firing. Figure 9 schematizes the experimental paradigm, the wrist joint, and the various populations of muscle, joint and cutaneous mechanoreceptors that

\section{Parkinsonian}

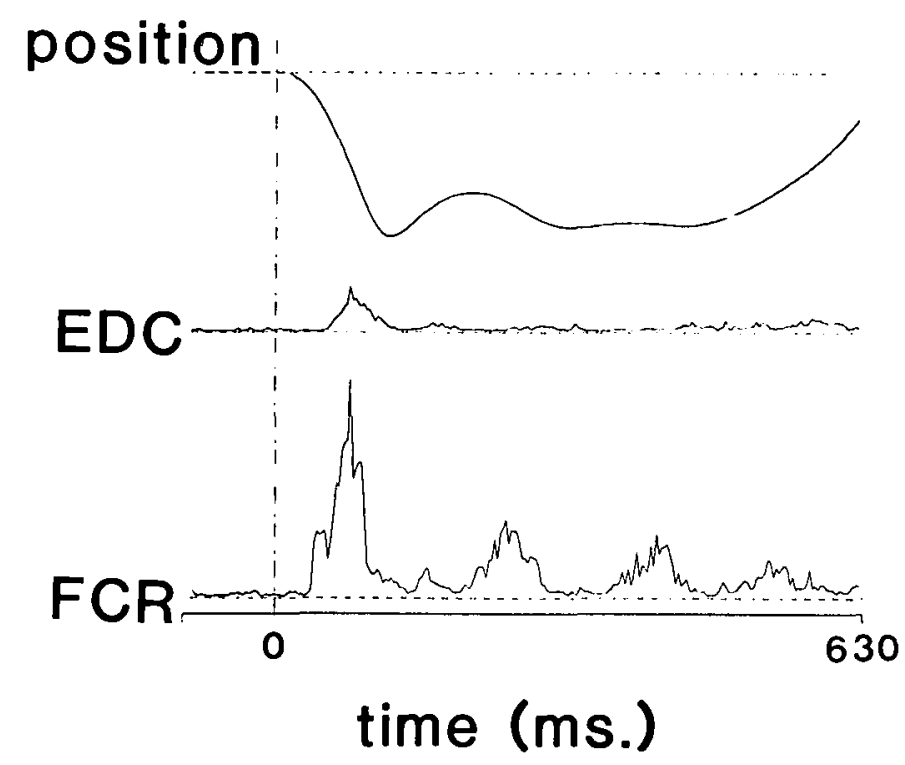

Figure 5-Record illustrating the paradoxical excitation in the shortened muscle and the 6-10hz oscillation in the stretched muscle seen in rigid PKs.

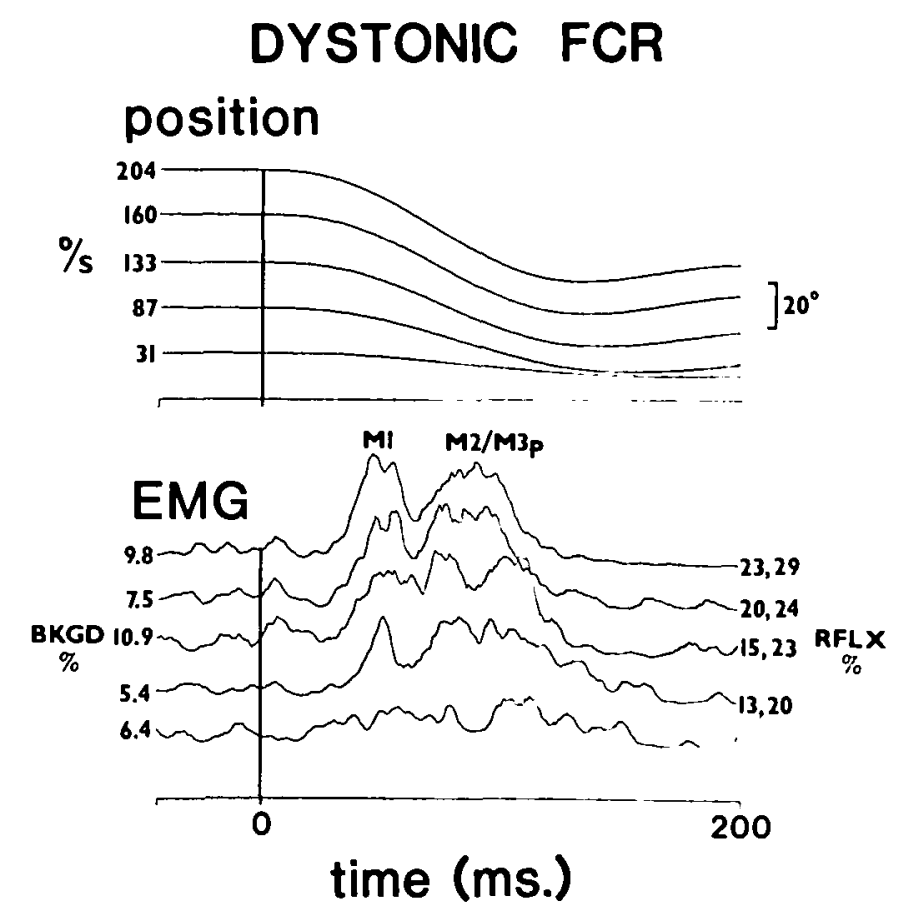

Figure 6 - Average records for wrist displacements in a patient with DMD. labelling and other conventions are identical to those in figure $I$.

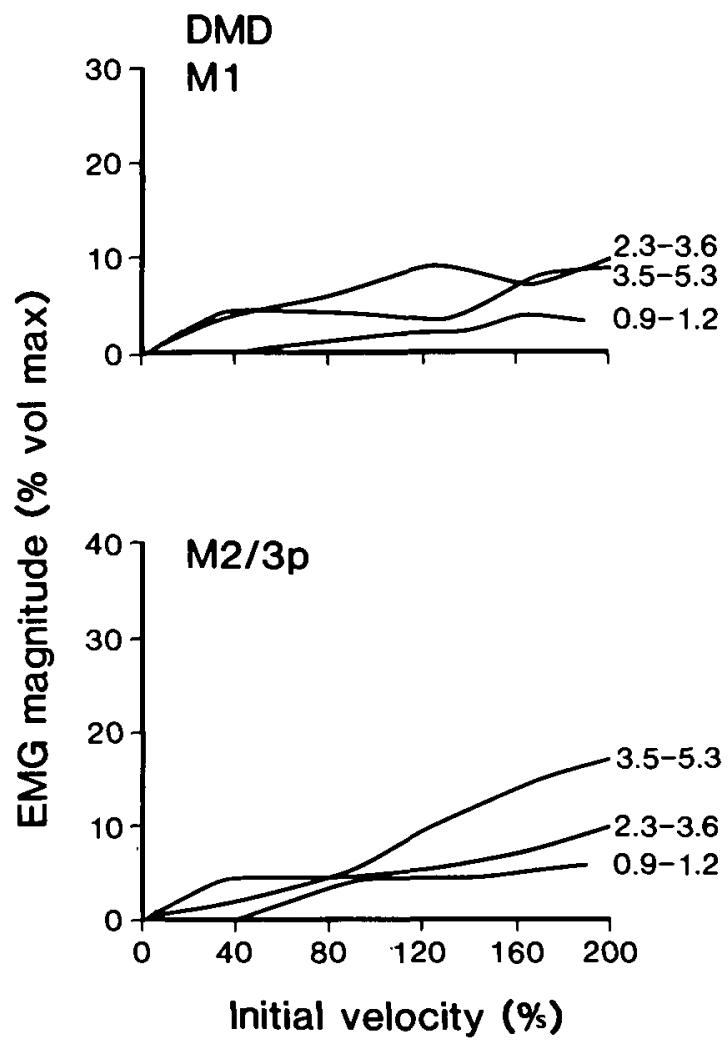

Figure 7 - Input-output plots relating $M /$ and $M 2-3 p$ magnitude to initial velocity in four DMD patients. Background levels are shown at the right end for each plot. 


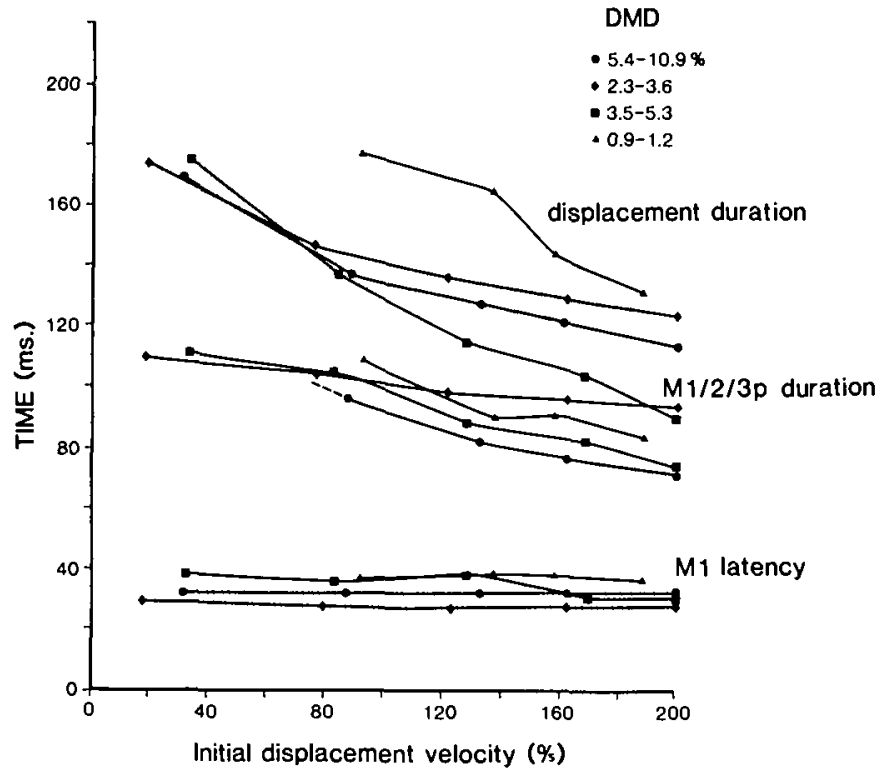

Figure 8-The dependence of the duration of the segmented responses on the displacement duration for DMD patients. Normal ranges taken from Bedingham and Tatton (1984) are indicated by the shaded areas. The dotted line in the single DMD patient (labelled with a circle) indicates that the magnitude of the reflex segments fell below the $3 S D$ level of preexisting BKGD activity at the lowest IV tested.

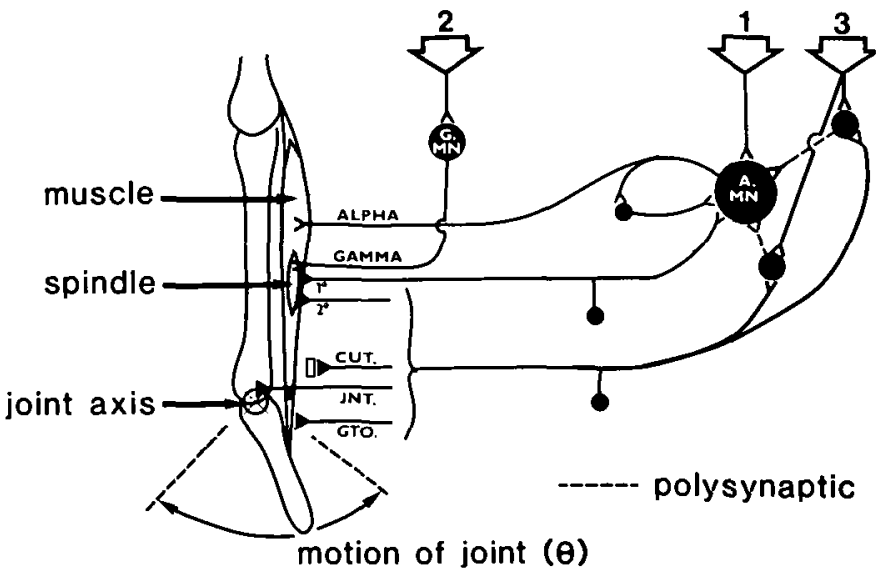

Figure 9-Schematic model of the experimental paradigm illustrating the afferents activated by imposed limb displacement and the mechanisms postulated to underly $P K$ rigidity (see details in text). Abbreviations: AMN, Alpha motoneuron; GMN, Gamma motoneuron; $1^{\circ}$, Primary Spindle afferents; $2^{\circ}$, Secondary Spindle afferents; CUT, Cutaneous afferents; JNT, Joint afferents: GTO, Golgi tendon organs.

likely are activated by the imposed angular joint displacements. The three arrows labelled 1, 2 and 3 are included to indicate the different abnormal mechanisms that have been proposed to underlie parkinsonian rigidity (for details and references see Tatton et al., 1979): (1) Increased descending drive to alpha motoneurons. The present study rules against this mechanism as the major cause of rigidity. High levels of background EMG would have been expected and the MI and/or the M2-3 segment would not have exceeded the upper surface of the volumes particularly at low background levels. In fact, we found that most of the parkinsonians examined demonstrated low resting background levels in contrast to the elderly normals studied by Evarts et al. (1979). (2) Increased descending drive to static gamma motoneurons. Recordings of single Ia fibers from muscle spindles in rigid parkinsonians using neurographic techniques (Burke et al., 1977) have not supported this mechanism. Furthermore, if the Ml segment receives a contribution from spindle afferent evoked motoneuron activity and static gamma drive was increased then both the M1 and the M2-3 segments would be expected to be similarly increased in magnitude. Complex scenarios could be proposed according to which increased gamma drive was phasically modulated so as to selectively alter the M2-3 segment but these are beyond the scope of our non-invasive studies to confirm or deny. (3) Increased excitation of interneurons in polysynaptic pathways activated by one or more of the mechanoreceptor populations offers the simplest mechanism to account for the increased M2-3 segment.

Recent research has unambiguously established that the long latency segments in the distal upper limb flexors in the primate are dependent on motor cortical integrity for their evolution (Lenz et al., 1983; see Wiesendanger and Miles, 1982 for a recent review) and that single motor cortical neurons do contribute to the generation of EMG activity during the $M 2$ segment in monkey wrist muscles (Cheney and Fetz, 1984; see Tatton et al., 1983 for a review comparing homology between reflex responses in monkey and human wrist muscles). Furthermore, Filion (1979) has shown increased levels of spontaneous activity in the globus pallidus internus (GPi) of monkeys rendered rigid and bradykinetic by midbrain lesions. The GPi projects to neurons in areas $x$ and VLo of the thalamus which in turn send axons to the supplementary motor area (SMA) and the arcuate premotor cortex (APA, see Wiesendanger 1981 for review of the connections and functions of the association and supplementary motor area). Both APA and SMA project in turn to the motor cortex.

It was previously proposed that increased GPi output reaching area 4 through the thalamus might abnormally facilitate the polysynaptic transcortical reflex (Tatton and Lee, 1975) and, thereby, result in increased M2-3 segments. Recent evidence firmly establishing the posit that transcortical reflex activity contributes to the generation of the long latency segments in the primate distal upper limb makes it tenable to consider that the interneuron in figure 9 receiving the increased drive to be located in the motor cortex. Yet, this suggestion is at best speculative until the functional operation of the linkages between GPi and area 4 are better defined. In fact, the interneuron(s) could be just as easily located within spinal polysynaptic circuits which receive increased descending facilitory drive and terminate predominantly on the "fast" motoneuron population (see Bawa and Tatton, 1979). In fact, the increase in the M2-3 segments in rigid PK patients may not reflect an abnormality in the mechanisms which generate the M2-3 segments in normals. The M2-3 activity may be summed with appropriately-timed activity which is not evoked in non-rigid subjects.

Lee and Tatton (1982) showed that tendon taps at the wrist evoke activity over the interval of the $M 1$ segment while angular displacements evoke both the M1 and M2-3 segments. Mortimer and Webster (1979) reported a high correlation between a mechanical measure of parkinsonian rigidity and the relative 
size of the M2-3 segment. The normal or even slightly decreased M1 segments is in keeping with the usual clinical finding of normal tendon jerks in rigid parkinsonians, and it could be proposed parkinsonian rigidity is almost entirely due to mechanisms manifesting the increased M2-3 segments. This view should be taken with some caution since the Westphal phenomenon and the 6-10 hz oscillatory activity would also be expected to contribute to the muscle tension production underlying rigidity.

The continuation of evoked EMG activity in the DMD patients as long as the displacement continues is in sharp contrast to normal subjects and rigid parkinsonians who respond with constant duration responses to imposed step loads, independent of displacement duration (Bedingham and Tatton, 1984). Previously, $\mathrm{H}$ reflex studies have failed to reveal a characteristic abnormality in DMD (Sax et al., 1976). The failure of the activity to terminate in a manner similar to normals may indicate dysfunction in an inhibitory mechanism which limits the duration of the reflex response. This may be one aspect of a generalized failure in sensorimotor mechanisms designed to limit the time course of motoneuron activity. Yet, other abnormalities such as increased sensitivity to one or more movement variables must be also considered. Studies using other imposed inputs with variable acceleration profiles (see Bedingham and Tatton, 1984) may serve to better define this apparent reflex abnormality and provide information regarding the mechanoreceptor populations crucial to the maintenance of constant duration responses.

In any case, the two extrapyramidal disorders, both characterized by abnormal muscle tone, show strikingly different abnormalities in their EMG responses to step load imposed wrist displacements. In rigid parkinsonian patients there is an abnormality in reflex amplitude control, specifically increased sensitivity of the mechanisms generating the M2-3 segment to one or more parameters of the imposed movement, while duration control remains intact. DMD patients have normal reflex amplitudes but present a failure in duration control.

\section{ACKNOWLEDGEMENTS}

The research was supported by MRC Grant MT 5218 and a Dystonia Foundation Grant. W.B. was supported by a Dystonia Foundation Studentship. The authors gratefully acknowledge R. Andrews for computer programing and $C$. Lawless for manuscript preparation.

\section{REFERENCES}

Bawa $P$ and Tatton WG (1979) Motor unit responses in muscles stretched by imposed displacements of monkey wrist. Exp. Brain Res. 37: 417-438.

Bedingham W and Tatton WG (1984) Dependence of EMG responses evoked by imposed wrist displacements on pre-existing levels of activity in the stretched muscles. Can. J. Neurol. Sci. (this issue)

Berardelli A, Sabra AF and Hallet M (1983a) Physiological mechanisms of rigidity. J. Neurol. Neurosurg. Psychiat. 46: 45-53.

Berardelli A, Sabra AF, Hallett M, Berenberg W and Simon SR (1983b) Stretch reflex of triceps surae in patients with upper motor neurone syndromes. J. Neurol. Neurosurg. Psychiat., 46: 54-60.

Burke D, Hagbarth KE and Wallin BG (1977) Reflex mechanisms in Parkinson rigidity. Scand. J. Rehab. Med. 9: 125-23.

Chan CWY, Kearney RE and Melvill Jones G (1979) Tibialis anterior response to sudden ankle displacements in normal and Parkinsonian subjects. Brain Res., 173: 303-314.
Cheney PD and Fetz EE (1984) Primate cortical motoneuronal cells contribute to long latency stretch reflexes. J. Physiol. In Press.

Delong MR and Georgopoulos AP (1981) Motor functions of the basal ganglia. In: Handbook of Physiology. Section I: The Nervous System. eds. Brookhart, J.M. and Mountcastle, V.B., Vol. 2, part 2, pp. 1017-1061.

Evarts EV, Teravainen H, Beuchert DE and Calne DB (1979) Pathophysiology of motor performance in Parkinson's disease. In: Dopaminergic Ergot Derivatives and Motor Functions. eds. K. Fuxe and D.B. Calne, London: Pergamon, pp. 45-59.

Filion M (1979) Effects of interruption of the nigrostriatal pathway and of dopaminergic agents on the spontaneous activity of globus pallidus neurons in the awake monkey. Brain Res. 178: 425-441.

Lee RG and Tatton WG (1975) Motor responses to sudden limb displacements in primates with specific CNS lesions and in human patients with motor system disorders. Can. J. Neurol. Sci. 2: 285-293.

Lee RG and Tatton WG (1978) Long loop reflexes in humans: clinical application. In: Cerebral Motor Control in Man: Long Loop Mechanisms, ed. Desmedt. J.E., Prog. Clin. Neurophysiol. Karger, Basel, 4: 229-245.

Lee RG and Tatton WG (1982) Long latency reflexes to imposed displacements of the human wrist: Dependence on duration of movement. Exp. Brain Res. 45: 207-216.

Lenz FA, Tatton WG and Tasker RR (1983) The effect of cortical lesions on the electromyographic response to joint displacement in the squirrel monkey forelimb. J. Neurosci. 3: 795-805.

Marsden DC, Harrison MJG and Bundey S (1976) Natural history of idiopathic torsion dystonia. Adv. Neurol. 14: 171-187.

Mortimer JA and Webster DD (1978) Relationships between quantitative measures of rigidity and tremor and the electromyographic responses to load perturbations in unselected normal subjects and Parkinson patients. In: Progress in Clinical Neurophysiology, Vol 4: Cerebral Motor Control in Man: Long Loop Mechanisms. ed. Desmedt, J.E., Karger, Basel, pp. 342-360.

Mortimer JA and Webster DD (1979) Evidence for a quantitative association between EMG stretch responses and Parkinsonian rigidity. Brain Res., 162: 169-173.

Noth J, Friedmann HH, Podoll K and Lange HW (1983) Absence of long latency reflexes to imposed finger displacements in patients with Huntington's disease. Neurosci. Letters, 35: 97-100.

Rothwell JC. Obeso JA, Traub MM and Marsden CD (1983) The behaviour of long-latency stretch reflex in patients with Parkinson's disease. J. Neurol. Neurosurg. Psychiat. 46: 35-44.

Sax DS, Johnson TL and Cooper IS (1976) Reflex dynamics in extrapyramidal disorders. Dystonia. Adv. Neurol. 14: 285-296.

Stein RB and Lee RG (1981) Tremor and clonus. In: Handbook of Physiology, Section I: The Nervous System, eds. Brookhart, J.M. and Mountcastle, V.B., Vol. 2, part 1, pp. 325- 343.

Struppler F, Lehmann-Horn F, Klein W, Lucking $\mathrm{CH}$ and Deuschl G (1984) Effect of stereoencephalotomy on long-latency EMG responses and motor control of arm movements in Parkinson's syndrome. Adv. Neurol. 40: 437-445.

Tatton WG and Lee RG (1975) Evidence of abnormal long-loop reflexes in rigid Parkinsonian patients. Brain Res. 100: 671-676.

Tatton WG, Bawa P and Bruce IC (1979) Altered motor cortical activity in extrapyramidal rigidity. Adv. Neurol. 24: 141-160.

Tatton WG, North AGE, Bruce IC and Bedingham W (1983) Electrompographic and motor cortical responses to imposed displacements of the cat elbow: disparities and homologies with those of the primate wrist. J. Neurosci., 3: 1807-1817.

Verrier MC, Tatton WG and Blair RDG (1984) Characteristics of EMG responses to imposed limb displacement in patients with vascular hemiplegia. Can. J. Neurol. Sci. (this issue)

Wiesendanger $M$ (1981) Organization of secondary motor areas of cerebral cortex. In: Handbook of Physiol. Section 1: The nervous system. eds. Brookhart, J.M. and Moutcastle, V.B. Vol. 2, Part 2, pp. 1121-1148.

Wiesendanger and Miles (1982) Ascending pathway to low threshold muscle afferents to the cerebral cortex and its possible role in motor control. Physiol. Rev. 62: 1234-1270. 